\title{
A Novel Population of Cholinergic Neurons in the Macaque Spinal Dorsal Horn of Potential Clinical Relevance for Pain Therapy
}

\author{
Sophie Anne Pawlowski, ${ }^{1}$ Stéphane Gaillard, ${ }^{1}$ Imad Ghorayeb, ${ }^{2}$ Alfredo Ribeiro-da-Silva, ${ }^{3}$ Rémy Schlichter, ${ }^{1,4}$ \\ and Matilde Cordero-Erausquin ${ }^{1}$ \\ ${ }^{1}$ Institut des Neurosciences Cellulaires et Intégratives, Unité Propre de Recherche 3212, Centre National de la Recherche Scientifique, Department \\ Nociception et Douleur, Strasbourg Cedex 67084, France, ${ }^{2}$ Université de Bordeaux 2, Institute of Neurodegenerative Disease, Centre National de la \\ Recherche Scientifique-Unité Mixte de Recherche 5293, Bordeaux Cedex 33076, France, ${ }^{3}$ Departments of Pharmacology \& Therapeutics and Anatomy \& \\ Cell Biology, McGill University, Montréal H3G 1Y6, Canada, and ${ }^{4}$ Université de Strasbourg, Strasbourg Cedex 67084, France
}

Endogenous acetylcholine (ACh) is a well-known modulator of nociceptive transmission in the spinal cord of rodents. It arises mainly from a sparse population of cholinergic interneurons located in the dorsal horn of the spinal cord. This population was thought to be absent from the spinal cord of monkey, what might suggest that spinal ACh would not be a relevant clinical target for pain therapy. In humans, however, pain responses can be modulated by spinal ACh, as evidenced by the increasingly used analgesic procedure (for postoperative and labor patients) consisting of the epidural injection of the acetylcholinesterase inhibitor neostigmine. The source and target of this ACh remain yet to be elucidated. In this study, we used an immunolabeling for choline acetyltransferase to demonstrate, for the first time, the presence of a plexus of cholinergic fibers in laminae II-III of the dorsal horn of the macaque monkey. Moreover, we show the presence of numerous cholinergic cell bodies within the same laminae and compared their density and morphological properties with those previously described in rodents. An electron microscopy analysis demonstrates that cholinergic boutons are presynaptic to dorsal horn neurons as well as to the terminals of sensory primary afferents, suggesting that they are likely to modulate incoming somatosensory information. Our data suggest that this newly identified dorsal horn cholinergic system in monkeys is the source of the ACh involved in the analgesic effects of epidural neostigmine and could be more specifically targeted for novel therapeutic strategies for pain management in humans.

\section{Introduction}

In rodents, spinal acetylcholine (ACh) levels are known to play a major role in pain-related behavior (Zhuo and Gebhart, 1991; Naguib and Yaksh, 1994; Hama and Menzaghi, 2001; Rashid and Ueda, 2002; Jones and Dunlop, 2007; Matsumoto et al., 2007), and the endogenous spinal cholinergic system has been shown to be involved in the effects of clinically relevant analgesics, such as morphine and clonidine (Chen and Pan, 2001; Paqueron et al., 2001). We have recently demonstrated that a sparse population of spinal dorsal horn cholinergic neurons, characterized by choline

Received Aug. 16, 2012; revised Dec. 17, 2012; accepted Dec. 20, 2012.

Author contributions: S.A.P., A.R.-d.-S., R.S., and M.C.-E. designed research; S.A.P., S.G., A.R.-d.-S., and M.C.-E. performed research; I.G. contributed unpublished reagents/analytic tools; S.A.P., S.G., A.R.-d.-S., R.S., and M.C.-E. analyzed data; A.R.-d.-S. and M.C.-E. wrote the paper.

This work was supported by Fondation pour la Recherche Médicale and the Samuel de Champlain program of the 63 C Commission Permanente de Coopération Franco-Québécoise to M.C.-E., Canadian Institute of Health Research Grant MOP-79411 to A.R.-d.-S., and French Ekbom Association donation to I.G. We thank Dr. R. H. Edwards (University of (alifornia San Francisco) for the generous gift of the anti-VAChT antibody and Johanne Ouellette for EM expertise.

The authors declare no competing financial interests.

Correspondence should be addressed to Dr. Matilde Cordero-Erausquin, Institut des Neurosciences Cellulaires et

Intégratives, Unité Propre de Recherche 3212, Centre National de la Recherche Scientifique, Department Nociception et Douleur, 21 rue René Descartes, 67084 Strasbourg Cedex, France. E-mail: cordero@unistra.fr.

DOI:10.1523/JNEUROSCI.3954-12.2013

Copyright $\odot 2013$ the authors $\quad 0270-6474 / 13 / 333727-11 \$ 15.00 / 0$ acetyltransferase (ChAT, the ACh synthesizing enzyme) immunoreactivity, represents the main source of ACh in the mouse spinal dorsal horn (Mesnage et al., 2011).

Clinical evidence suggests that spinal ACh also modulates pain behavior in humans. Indeed, acetylcholinesterase (AChE) inhibitors, such as neostigmine, are analgesic in postoperative and labor patients after epidural injection (for review, see Habib and Gan, 2006; Eisenach, 2009). AChE inhibitors act by increasing the levels of ACh that in this case can be released either by intrinsic spinal neurons, as observed in mice, or by spinally projecting neurons. Either of these potential sources is poorly documented in humans; and based on monkey anatomical data, a cholinergic system was even thought to be absent from primate dorsal horn (see below).

ChAT enzymatic activity has been detected in samples from human dorsal spinal cord (Aquilonius et al., 1981); but of the three studies describing the presence of ChAT immunolabeling in the human spinal cord (Schafer et al., 1995; Oda et al., 2004; Gill et al., 2007), only one mentions ChAT-immunoreactive (IR) fibers and/or cell bodies in the dorsal horn of some, but not all, humans (without obvious correlation with age or sex) (Gill et al., 2007). When present, these ChAT-IR fibers and neurons are reported as being in laminae II-V. The criteria used to identify the 
layers and the spinal segments in which they were observed are not specified in the article. Regarding studies in the monkey, none of the studies describing ChAT immunostaining in the spinal cord mentions the dorsal horn, what might suggest that this region, involved in sensory processing, might be devoid of intrinsic cholinergic neurons (Hedreen et al., 1983; Schafer et al., 1995; Ichikawa and Shimizu, 1998). The clinical and anatomical human data presented above yet raise the possibility that intrinsic cholinergic interneurons are indeed present in the primate spinal dorsal horn, as in rodents, but might have been overlooked because of technical issues (including tissue preservation).

To address this issue, we used immunocytochemistry to perform a detailed analysis of cholinergic labeling in the dorsal horn of macaque monkey, both with light and electron microscopy (EM). Our primary aim was to identify the source and targets of ACh involved in the analgesic properties of epidural AChE inhibitors, to provide the basis for a less empirical and more efficient approach to this new therapy. The identification and characterization of this cholinergic neuronal population in the monkey spinal dorsal horn, with morphological features suggesting that it can modulate nociceptive transmission, open new avenues for pain therapy.

\section{Materials and Methods}

\section{Animals}

Monkeys. This study was performed on spinal cord tissue from male and female adult rhesus monkeys (Macaca fascicularis) that have been killed for other experimental purposes in two different locations, as described below. The light microscopy immunochemical analyses regarding the distribution of ChAT-positive neurons were performed on lumbar and cervical spinal cord tissue from three monkeys prepared at Segalen University (Bordeaux, France). The EM analyses were conducted on cervical spinal cord tissue prepared from three monkeys at McGill University (Montreal, Quebec, Canada).

Mice. For the sake of comparison, we also performed some new experiments on mice. Adult male CD1 mice were housed four or five per cage in a colony maintained at constant temperature $\left(23^{\circ} \mathrm{C}\right)$ with a $12 \mathrm{~h} \mathrm{light/}$ dark cycle and ad libitum food and water. The animal facilities are legally registered for animal experimentation under Animal House Agreement B67-482-1/C67-482-1 and scientists in charge of the experiments possess the certificate authorizing experimentation on living animals, delivered by the governmental veterinary office. All procedures were performed in accordance with the local animal care and use committee as well as with European Communities Council Directive 86/6609/EEC.

\section{Tissue preparation for light microscopy}

Tissue for the light microscopic component of this study originated from Segalen University (Bordeaux, France), where monkeys were perfused intracardially with $4 \%$ PFA in $0.1 \mathrm{~m}$ phosphate buffer, $\mathrm{pH}$ 7.4. Blocks of cervical and lumbar spinal cord were postfixed for $24 \mathrm{~h}$ in a $4 \%$ PFA solution at $4^{\circ} \mathrm{C}$, and then immersed in $30 \%$ sucrose in phosphate buffer for $72 \mathrm{~h}$ at $4^{\circ} \mathrm{C}$ for cryoprotection before being snap frozen with isopentane at $-5^{\circ} \mathrm{C}$. Subsequently, tissue was stored for two years at $-80^{\circ} \mathrm{C}$. Then free-floating serial sections (30- or 50- $\mu \mathrm{m}$-thick) from the lumbar enlargement (segments L6-L7) or from cervical segments (C5-C6) were cut in the transverse or parasagittal planes using a cryostat (Microm HM 560 or Leica CM3050S).

Mice were deeply anesthetized with pentobarbital $(0.15 \mathrm{ml}$ intraperitoneal injection) and perfused transcardially with $0.1 \mathrm{M}$ phosphate buffer for $2 \mathrm{~min}$ and with $4 \%$ PFA in phosphate buffer for $18 \mathrm{~min}$. Whole backs were postfixed overnight in a $4 \%$ PFA solution at $4^{\circ} \mathrm{C}$, and spinal cords were dissected after laminectomy. Serial sections (50- $\mu \mathrm{m}$-thick) of lumbar enlargement (segments L4-L6), in the transverse plane, were performed using a vibrating microtome (Leica, VT1000S).

All sections were collected and stored at $4^{\circ} \mathrm{C}$ in PBS for a maximum of 1 month until immunocytochemical processing.

\section{Immunohistochemistry}

The immunohistochemistry for light microscopy was entirely performed at room temperature. Free-floating sections were washed $(3 \times 10 \mathrm{~min})$ in PBS, and endogenous peroxidases were quenched with $50 \%$ ethanol/ $1 \%$ $\mathrm{H}_{2} \mathrm{O}_{2}$ for $15 \mathrm{~min}$. Sections were washed $(3 \times 10 \mathrm{~min})$ in PBS and incubated in $5 \%$ normal donkey serum (NDS)/PBS/0.5\% Triton X-100 (PBS-t; Sigma) for $20 \mathrm{~min}$. Subsequently, sections were incubated overnight in the primary antibodies diluted in PBS-t with $1 \%$ NDS. Sections were washed $(3 \times 10 \mathrm{~min})$ in PBS and incubated for $1 \mathrm{~h}$ with biotinylated secondary antibodies in 1\% NDS/PBS-t. Sections were then washed in PBS $(3 \times 10 \mathrm{~min})$ and incubated with PBS-t containing an avidin-biotinperoxidase complex (ABC Elite, $0.2 \% \mathrm{~A}$ and $0.2 \% \mathrm{~B}$; Vector Laboratories) for $2 \mathrm{~h}$. After washing in Tris- $\mathrm{HCl}$ buffer $(0.05 \mathrm{M}, \mathrm{pH} 7.5 ; 3 \times 10$ $\mathrm{min})$, peroxidase was revealed by incubation in $3,3^{\prime}$-diaminobenzidine tetrahydrochloride $(\mathrm{DAB})$ solution with hydrogen peroxide $(0.025 \%$ $\mathrm{DAB}, 0.0006 \% \mathrm{H}_{2} \mathrm{O}_{2}$; Sigma) in Tris- $\mathrm{HCl}$ buffer for 5-10 min and washed again in Tris- $\mathrm{HCl}$ buffer.

The isolectin B4 (IB4) staining procedure was also entirely performed at room temperature. Free-floating sections were washed $(3 \times 10 \mathrm{~min})$ in PBS, and endogenous peroxidases were quenched with $50 \%$ ethanol $/ 1 \%$ $\mathrm{H}_{2} \mathrm{O}_{2}$ for $15 \mathrm{~min}$. Sections were washed $(3 \times 10 \mathrm{~min})$ in PBS and incubated with biotinylated Griffonia (bandeiraea) simplicifolia IB4 (Vector Laboratories, B-1205) at 1/200 in PBS-t overnight. Sections were then washed in PBS $(3 \times 10 \mathrm{~min})$ and incubated with PBS-t containing ABC for $2 \mathrm{~h}$. After washing in Tris-HCl buffer $(3 \times 10 \mathrm{~min})$, bound peroxidase was revealed by incubation in DAB solution with $\mathrm{H}_{2} \mathrm{O}_{2}$ for 6 min followed by washing in Tris- $\mathrm{HCl}$ buffer.

Sections were mounted on gelatin-coated slides, air-dried overnight and then dehydrated in ascending ethanol concentrations, and defatted in Roti-Histol (Carl Roth). Finally, slides were coverslipped with Eukitt (O. Kindler).

\section{Immunofluorescence}

Free-floating sections were washed $3 \times 10 \mathrm{~min}$ in PBS and incubated in $5 \%$ NDS/PBS-t for $20 \mathrm{~min}$. Subsequently, sections were incubated overnight in the primary antibodies solution (antibodies were diluted in PBS-t with $1 \%$ NDS). Sections were then washed $(3 \times 10 \mathrm{~min})$ in PBS and incubated for $1 \mathrm{~h}$ in secondary antibodies (protected from light) diluted in PBS-t. Finally, sections were washed $3 \times 10 \mathrm{~min}$ in PBS, mounted on gelatin-coated slides, and coverslipped with a fluorescence mounting medium (Dako, S3023). All steps were performed at room temperature under constant agitation.

\section{Tissue preparation for EM}

The preparation of the material for the electron microscopic component of this study was entirely performed at McGill University several years before the light microscopic studies. Three macaque monkeys were deeply anesthetized with sodium pentobarbital, then perfused transcardially with saline followed by a mixture of $4 \%$ PFA and $0.5 \%$ glutaraldehyde in $0.1 \mathrm{M}$ PB for $30 \mathrm{~min}$. Segments C5-C7 of the spinal cord were collected and further fixed by immersion in the same fixative mixture without glutaraldehyde for $2 \mathrm{~h}$ at $4^{\circ} \mathrm{C}$, and then immersed in $30 \%$ sucrose in phosphate buffer, for $24-48 \mathrm{~h}$ at $4^{\circ} \mathrm{C}$ for cryoprotection. The lumbar segments of these animals were not available for this study as they were used for other experimental purposes. The tissue was trimmed in small blocks with a maximum of $0.5 \mathrm{~cm}$ in thickness and snap frozen in liquid nitrogen, followed by thawing in phosphate buffer at room temperature. Subsequently, $50-\mu \mathrm{m}$-thick Vibratome sections were cut and collected in PBS. Segments C6-C7 were cut in the transverse plane, and segment C5 was cut parasagittally. Sections were treated with $1 \%$ sodium borohydride in PBS for 30 min and then extensively washed in PBS for $60 \mathrm{~min}$ until all bubbling disappeared.

\section{Immunohistochemistry for EM}

The sections were then incubated overnight at $4^{\circ} \mathrm{C}$ in a rabbit polyclonal serum against the vesicular acetylcholine transporter (VAChT; 1:10,000) (Gilmor et al., 1996) in PBS. All subsequent steps were performed at room temperature. After $2 \times 15$ min washing in PBS, sections were incubated for $1 \mathrm{~h}$ in biotinylated goat anti-rabbit IgG (IgG) (1:800 in 5\% normal goat serum; Vector Laboratories), followed by $1 \mathrm{~h}$ incubation in 
an $A B C$ complex (1:400, Vector Laboratories). After further washing, the antigenic sites were revealed by reacting the sections in DAB and $\mathrm{H}_{2} \mathrm{O}_{2}$ with double intensification (Adams, 1981), as previously described (Ribeiro-da-Silva et al., 1993).

After extensive washing in PBS $(3 \times 10 \mathrm{~min})$, the sections were incubated in $1 \%$ osmium tetroxide in PB for $1 \mathrm{~h}$ at room temperature. Finally, the sections were dehydrated in ascending alcohol concentrations and propylene oxide, and flat embedded in Epon as previously described (Ribeiro-da-Silva et al., 1993). After polymerization of the Epon, the sections were examined by light microscopy and the selected fields (a region of the spinal cord comprising laminae I-III) were reembedded in Epon blocks. It is well known that Epon blocks of osmicated tissues can be stored indefinitely at room temperature without any deterioration of the material. In our case, the blocks were stored for up to 15 years before being trimmed for EM examination and cut on a Reichert ultramicrotome using diamond knives. The ultrathin sections were collected onto formvar-coated one-slot grids, contrast stained with uranyl acetate and lead citrate, and observed with a FEI/Philips CM120 electron microscope equipped with a Gatan digital camera.

For a double-labeling of VAChT with GABA, ultrathin sections from blocks of material immunostained for VAChT were cut and collected onto mesh nickel grids. Postembedding immunostaining for GABA was performed as described in detail previously (Ribeiro-da-Silva et al., 1993). After washes in Tris-buffered-saline, an anti-rabbit IgG antibody conjugated to $10 \mathrm{~nm}$ gold (Biocell) was used. After counterstaining with uranyl acetate and lead citrate, the sections were examined under the electron microscope.

\section{Antibodies}

Antibodies used in this study were as follows: ChAT (1:1000 for immunohistochemistry and 1:500 for immunofluorescence; goat polyclonal against human placental ChAT, Millipore, AB 144P), calcitonin generelated peptide (CGRP,1:10,000; sheep polyclonal against rat $\alpha$-CGRP conjugated to BSA, Enzo Life Sciences, CA 1137-0025), protein kinase C gamma (PKC $\gamma, 1 / 2500$; rabbit polyclonal against mouse PKC $\gamma$ residues 679-697, Santa Cruz Biotechnology, SC211), neuronal nuclei (NeuN, 1/5000; mouse anti-NeuN, Millipore, MAB377), VAChT (1:10,000; rabbit polyclonal serum raised against rat VAChT residues 478-530) (Gilmor et al., 1996), and GABA (1:200; rabbit polyclonal IgG, Sigma, A2052). For detection, species-specific secondary antibodies were used: anti-goat IgG biotinylated (1:200; Vector Laboratories, BA-9500), antirabbit IgG biotinylated (1:200; GE Healthcare, RPN1004V), anti-mouse IgG biotinylated (1:200; Vector Laboratories, BA-2001), anti-rabbit IgG conjugated to $10 \mathrm{~nm}$ gold (1:50; Biocell), anti-goat IgG conjugated to Cy3 (1:400; Jackson ImmunoResearch Laboratories, 705-165-003).

\section{Image analysis}

For light microscopy, the sections were examined with a Nikon Eclipse E600 microscope linked to a camera lucida system (Nikon Y-IDT) and digital camera or with a Zeiss Axioplan 2 imaging microscope equipped with a Zeiss high-resolution digital camera. The dorsoventral distribution of markers (ChAT-, PKC $\gamma_{-}$-, CGRP-, NeuN-, and IB4-labeled terminals) was analyzed as previously described (Lorenzo et al., 2008; Mesnage et al., 2011). A $465 \times 1110 \mu \mathrm{m}$ (for monkey spinal cord) or $147 \times 250$ $\mu \mathrm{m}$ (for mouse spinal cord) rectangle was placed with one of the shorter sides at the edge of the gray matter. The "Plot Profile" function of ImageJ software (W. Rasband, National Institutes of Health) provided, for each pixel in the dorsoventral axis, the mean pixel intensity on a line parallel to the white matter. The values of the relative optical density (ROD) represent the mean pixel intensity per line standardized to the higher intensity level per section (after background subtraction). The analysis was performed on serial images stained for ChAT and PKC $\gamma$, CGRP, NeuN, or IB4 on the adjacent section. The error areas on the curves represent the SEM for 6 different sections from the same animal.

\section{ChAT-positive cell bodies counting and $3 D$ reconstructions}

A 1.755-mm-long segment of monkey lumbar spinal cord was cut in the midline and serial parasagittal sections $(30 \mu \mathrm{m})$ from one hemicord were obtained. After ChAT immunolabeling, the serial sections were observed under a microscope (Nikon eclipse E600) linked to a camera lucida
(Nikon Y-IDT). Contours of each section and outlines of the ChATpositive plexus were drawn; then every ChAT-positive cell body was marked as a dot, allowing counting.

\section{Allometric comparison of neuronal population densities across species}

To be meaningful, the comparison of the number (or density) of a specific neuronal population between species should take into account the difference in size of the two animals and the fact that biological constants usually increase with the size of the organism, but not in direct proportions (Pagel and Harvey, 1988). There is, rather, an allometric coefficient of $\sim 0.75$ between the logarithm of a biological constant and the logarithm of the mass (or volume) of the organism (or organ, or nervous area). This was first observed in the respiratory physiology field (Kayser and Heusner, 1964) and more recently extended to the neuroscience field with an allometric coefficient comprised between 0.695 (Mayhew, 1991) and 0.7810 (Gagliardo et al., 2005; Loesch et al., 2010). We therefore estimated the number of cholinergic neurons per segment in the lumbar enlargement of monkey [N(monkey)] and mouse [N(mouse)] and compared it with the volume of the corresponding segment in these two species [V(monkey) and $\mathrm{V}$ (mouse) $]$ by calculating the following allometric coefficient:

$[\log \mathrm{N}($ monkey $)-\log \mathrm{N}($ mouse $)] /[\log \mathrm{V}($ monkey $)-\log \mathrm{V}$ (mouse) $]$.

An allometric coefficient close to 0.75 suggests that the biological constant under study behaves like most biological constants and has not been subject to a differential selection pressure.

\section{Morphometric analysis}

The method to obtain quantitative morphometric parameters has been described previously (Mesnage et al., 2011). Briefly, neurons were reconstructed using Neurolucida (MBF Bioscience) or Neuromantic (http://www.reading.ac.uk/neuromantic). The images containing the reconstructed neuron were then saved as binary JPEG images for illustration and further analysis. The morphometric analysis was performed using the "Shape Descriptors" plugin in ImageJ (G. Chinga). The solidity is the ratio between the intrinsic area of the neuron and the area of a convex polygon encompassing the neuron and its processes (Russ, 1999). The aspect ratio is the ratio of the two axes of the smallest possible ellipse encompassing the neuron (Syverud et al., 2007). We also determined the angle between the long axis of this ellipse and the vertical axis of the image. The fractal dimension was calculated with the box counting method (Bernard et al., 2001) using Benoit software (Trusoft International). Because of the actual size of the neurons, the boxes' sizes were set from 1 to $20 \mu \mathrm{m}$ (Takeda et al., 1992). For each neuron, the ratio between the number of occupied boxes and the size of the boxes was plotted using a logarithmic scale. The linearity of this relationship was tested for each neuron included in this study: the linear correlation factor $(r)$ was always $>0.985$. This means that the neurons under study could be considered as fractal objects and the fractal dimension $(\mathrm{Db})$ was then defined as the opposite of the curve's slope:

$$
\log (\text { number of occupied boxes })=\log \mathrm{a}-\mathrm{Db} \times \log (\mathrm{box} \text { size }) .
$$

\section{Preparation of figures}

All figures were prepared in Illustrator CS5 (Adobe Systems). Contrast and/or brightness of micrographs were adjusted using PhotoShop CS5 (Adobe Systems).

\section{Results}

\section{ChAT immunostaining in the monkey vs mouse spinal cord}

ChAT immunostaining was analyzed on histological sections of monkey spinal cord. As previously observed (Hedreen et al., 1983; Schafer et al., 1995; Ichikawa and Shimizu, 1998), there was strong labeling of the ventral spinal cord, reflecting the presence of cholinergic motoneurons (Fig. $1 A, B$ ). However, labeling was also observed in the dorsal horn and consisted mostly of immunolabeled fibers (Figs. $1 A, B$ and $2 B, C$ ), although a few stained cell bodies were also found (Fig. $1 C$ ). This staining was similar in 
A

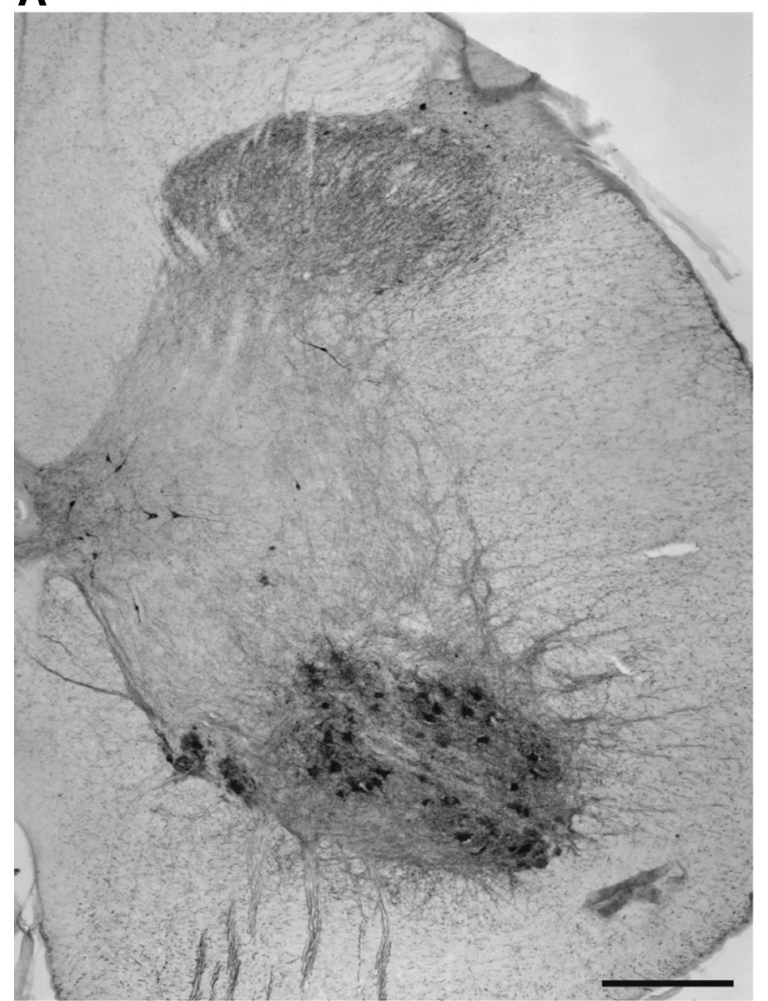

\section{C1}
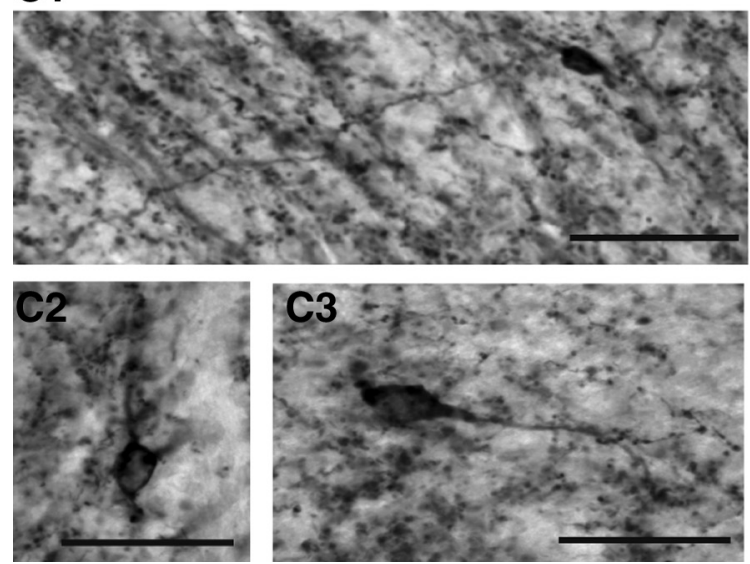

B

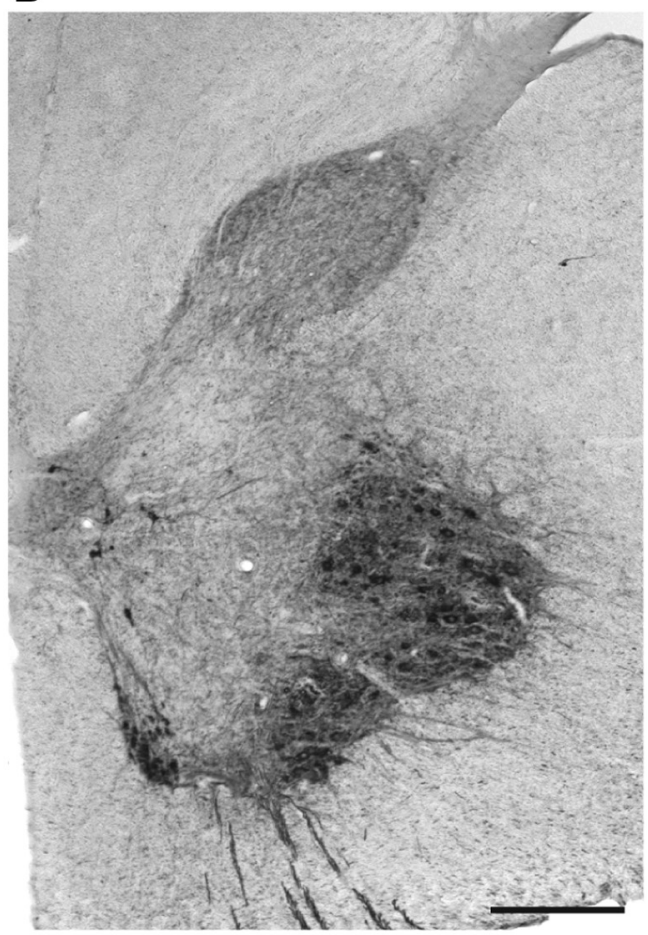

C4

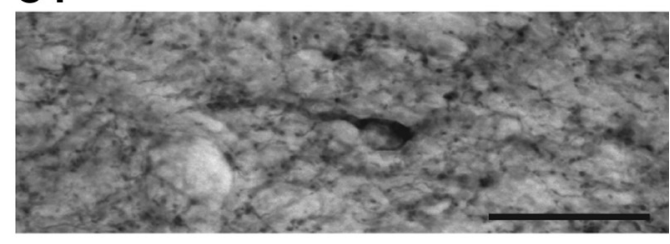

C5

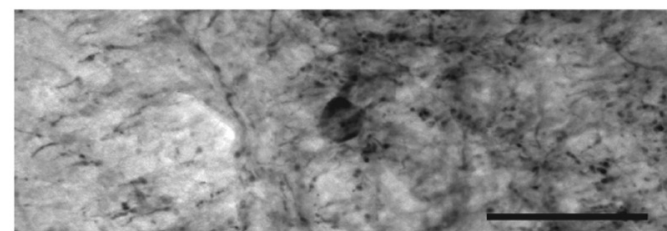

Figure 1. ChAT labeling in monkey spinal cord. A, ChAT labeling in a transverse section (50- $\mu \mathrm{m}$-thick) of monkey lumbar spinal cord. A strong cholinergic labeling of motoneurons is observed in the ventral part of the cord, some neurons are labeled around the central canal and deep dorsal horn, and a cholinergic plexus is present in the superficial dorsal horn. What is observed in the upper right edge of lamina I (next to the dorsal root entry zone) is a nonspecific deposit of DAB reaction product. $B$, ChAT labeling in a transverse section (30- $\mu \mathrm{m}$-thick) of monkey cervical spinal cord. $C$, High magnification of ChAT-positive neurons in transverse sections (30- $\mu \mathrm{m}$-thick) of monkey lumbar (C1-C3) or cervical (C4,C5) spinal cord. Scale bars: $A, B, 500 \mu \mathrm{m} ; C, 50 \mu \mathrm{m}$.

cervical (C5-C6) and lumbar (L6-L7) sections from monkey spinal cord (Figs. $1 A, B$ and 2B2,C2). Compared with a similar staining performed on mouse spinal cord sections (Fig. 2A), the plexus of ChAT-IR fibers appeared relatively thicker in the monkey dorsal horn compared with the mouse.

To quantify this species difference in distribution, we identified the localization of the cholinergic plexus using standard lamination criteria (Ribeiro-da-Silva, 2004; Lorenzo et al., 2008; Cordero-Erausquin et al., 2009). NeuN labeling performed on adjacent $50-\mu \mathrm{m}$-thick sections was used to assist in the delineation of the laminae of the dorsal spinal cord in both monkey and mouse. When plotting the intensity of NeuN signal along a dorsoventral axis in the superficial dorsal horn, we observed a first peak of NeuN signal (Fig. 2B3), located at $200 \mu \mathrm{m}$ from the dorsal border of the gray matter in monkey lumbar material ( $40 \mu \mathrm{m}$ in mouse, Fig. 2A3), that corresponded to the high density of small neurons in outer lamina II (IIo). Ventral to this peak, there was an area of less NeuN staining (at 400 and $60 \mu \mathrm{m}$ in monkey and mouse, respectively) corresponding to the lower density of small neurons in inner lamina II (IIi). The second peak of $\mathrm{NeuN}$ signal corresponded to the larger and denser neurons in lamina III. The comparison of the ChAT and NeuN labeling along a dorsoventral axis demonstrates that the cholinergic plexus in monkey lumbar and cervical cord covered laminae II and III, with a slightly lower density in the dorsal aspect of lamina IIi (Fig. $2 B, C$ ), whereas it was mostly restricted to lamina IIi in mouse (Fig. 2A). There was only light ChAT staining in lamina $I$ in both species. 


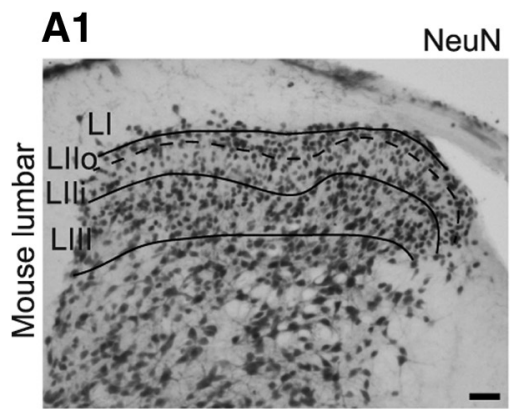

A2

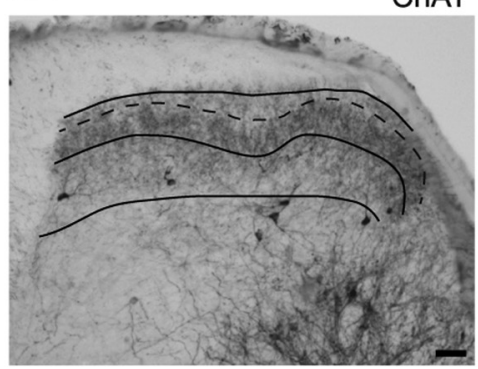

B1

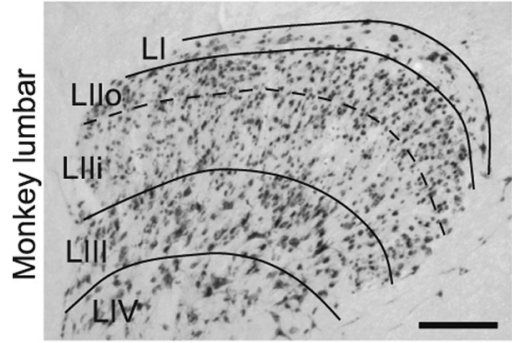

C1

NeuN

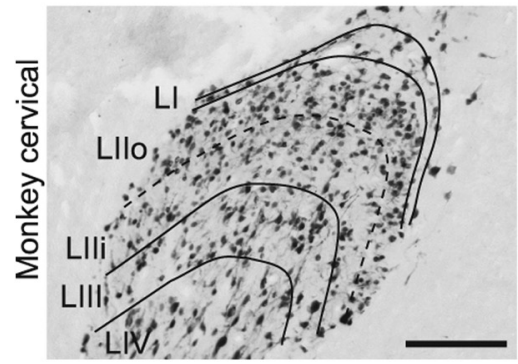

\section{B2}
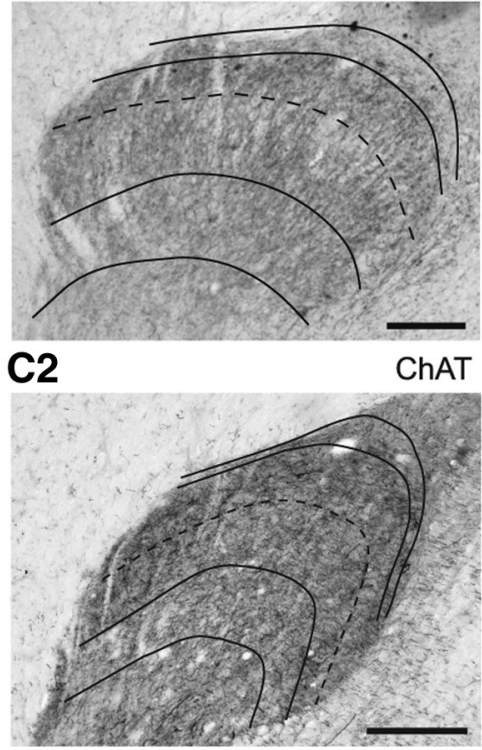

A3

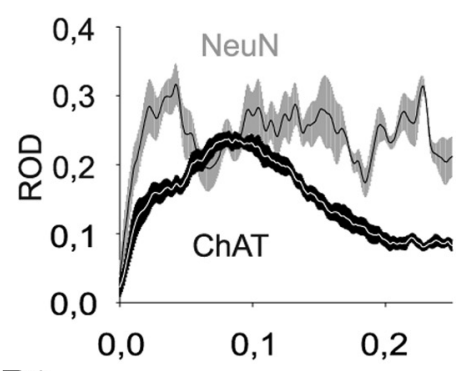

B3

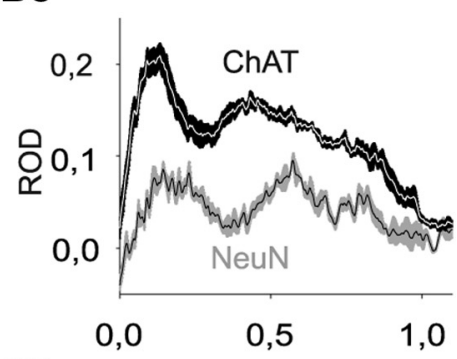

C3

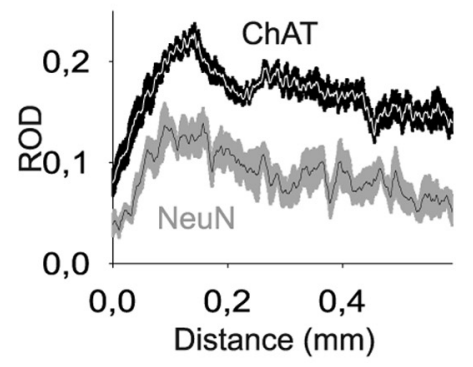

Figure 2. ChAT and NeuN labeling in mouse $(\boldsymbol{A})$ and monkey $(\boldsymbol{B}, \boldsymbol{C})$ spinal cord. $\boldsymbol{A}$, Comparison between NeuN $(\boldsymbol{A} \boldsymbol{1})$ and $C h A T(\boldsymbol{A} \boldsymbol{2})$ labeling in lumbar mouse spinal cord on adjacent transverse sections (50- $\mu \mathrm{m}$-thick). Graphic representation of the ROD of anti-NeuN (gray) and anti-ChAT (black) immunolabeling in the dorsal horn of mouse (A3). RODs were measured within a rectangle measuring $465 \times 1110 \mu \mathrm{m}$ (for monkey lumbar spinal cord), $240 \times 590 \mu \mathrm{m}$ (for monkey cervical spinal cord), or $147 \times 250 \mu \mathrm{m}$ (for mouse) placed with one of the shorter sides at the dorsal limit of the dorsal gray matter and centered in the mediolateral axis of the dorsal horn. The ROD values (obtained by the software along a line parallel to the shorter axis of the rectangle) were exported for every pixel along the dorsoventral axis. B1-B3, Equivalent to $A$ 1-A3 but represent monkey lumbar material. $\mathbf{C 1}$-C3, Represent monkey cervical material. For one animal (six sections), the data are mean \pm SEM. Scale bars: $A, 100 \mu \mathrm{m} ; \boldsymbol{B}, \mathbf{C}, 250 \mu \mathrm{m}$. LI, lamina I; Lllo, lamina Il outer part; Llli, lamina II inner part; LIII, lamina III; LIV, lamina IV.

Our data thus demonstrate the existence of a plexus of cholinergic fibers in the dorsal horn of the monkey spinal cord, with a laminar distribution that differs from the one observed in mouse.

\section{ChAT immunostaining in the monkey versus classical markers of the dorsal horn}

CGRP, IB4, and PKC $\gamma$ are classical markers of the superficial dorsal horn. We have previously shown in mouse that the ChAT plexus overlapped only with the denser band of PKC $\gamma$ staining, whereas it was ventral to the IB4 and CGRP staining (Mesnage et al., 2011). We therefore compared the localization of the ChAT plexus in monkey with these markers to further characterize it.

CGRP labeling was comparable to that described in the literature for monkey (Carlton et al., 1987), covering laminae I and IIo (Fig. 3A2). When comparing the distribution of the CGRP and ChAT signals along a dorsoventral axis, we could observe that the CGRP labeling started more dorsally than the ChAT plexus, confirming the limited lamina I ChAT labeling in the monkey that we had observed based on lamination identified with the NeuN staining. As in the mouse, the ChAT plexus ended more ventrally than the CGRP labeling (Fig. 3A3).

As far as we are aware, this study represents the first description of PKC $\gamma$ labeling in the primate dorsal horn. As in mouse and rat
(Polgar et al., 1999; Mesnage et al., 2011), the PKC $\gamma$ staining covered lamina IIo and IIi, with a denser band in lamina IIi. The difference in staining density between lamina IIo and IIi was slightly less marked in monkey than in rodents. In monkey, compared with the ChAT labeling (Fig. 3B3), we observed that the ChAT plexus was thicker than the PKC $\gamma$ one, whereas in mouse the ChAT staining overlapped only with the denser lamina IIi band of PKC $\gamma$ staining, although there is no colocalization of the signals (Mesnage et al., 2011).

Although the IB4 labeling has not been described to date in the monkey dorsal horn, there is a recent description in the human dorsal horn (Eftekhari and Edvinsson, 2011); the IB4 labeling we obtained in monkey (Fig. 3C) was very similar to that in human. The ChAT plexus overlapped with the IB4 band and extended ventrally to it in the monkey, whereas there was no overlap in the mouse (Mesnage et al., 2011).

Our data show that the relative position of the ChAT plexus with respect to CGRP, PKC $\gamma$, and IB4 staining differs in monkey and mouse, consistent with the thicker ChAT plexus in monkey.

ChAT-immunoreactive cell bodies in the monkey dorsal horn In addition to cholinergic fibers, ChAT immunoreactivity was also detected in cell bodies of the monkey dorsal horn. Although these were occasionally observed in transverse sections, they were 
A1

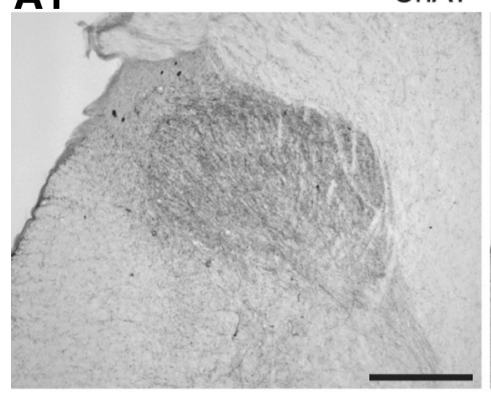

ChAT

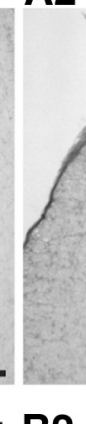

B1

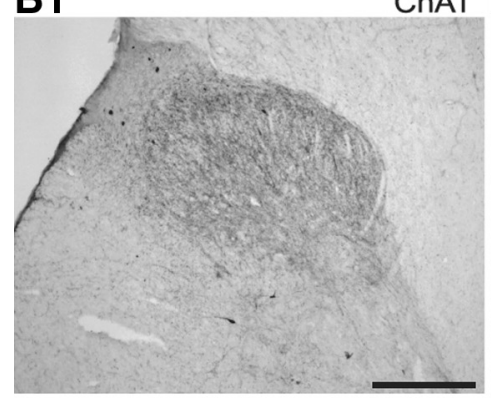

B2

ChAT C2

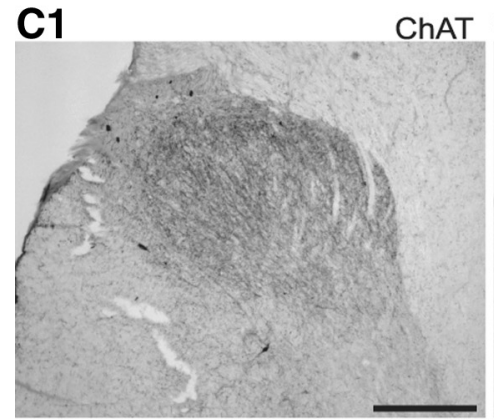

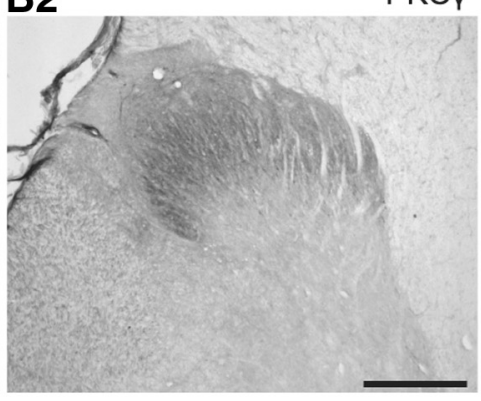

A2

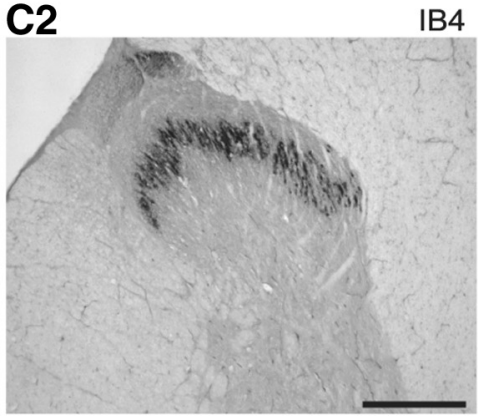

CGRP

\section{A3}

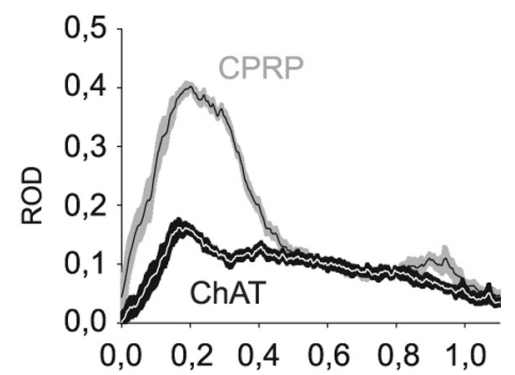

B3

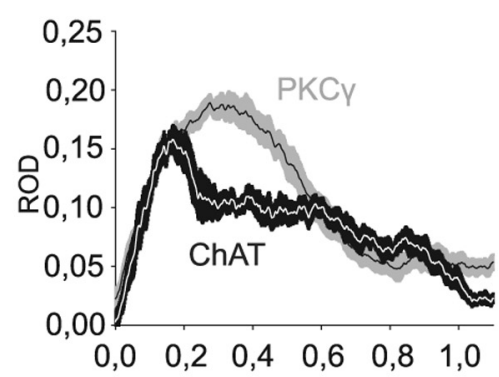

C3

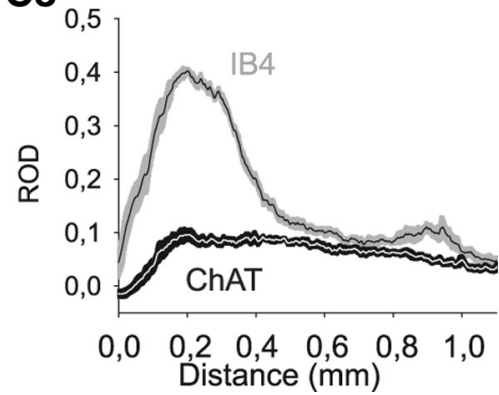

Figure 3. ChAT-immunopositive plexus compared with anti-CGRP, anti-PKC $\gamma$, or anti-IB4 immunolabeling in monkey lumbar spinal dorsal horn. $A$, Comparison of anti-ChAT (AT) and anti-CGRP immunolabeling (A2) on adjacent transverse sections of the dorsal horn (30- $\mu \mathrm{m}$-thick). Graphic representation (A3) of the mean \pm SEM ROD of ChAT (black) and CGRP (gray) staining (six sections, one animal). $\boldsymbol{B}$, Comparison of anti-ChAT (B1) and anti-PKC $\gamma(\boldsymbol{B} 2)$ immunolabeling on adjacent transverse sections of the dorsal horn (30- $\mu$ m-thick). Graphic representation (B3) of the mean \pm SEM ROD of the ChAT (black) and PKC $\gamma$ (gray) stainings (six sections, one animal). C, Comparison of anti-ChAT immunolabeling (C1) and IB4 staining (C2) on adjacent transverse sections of the dorsal horn (30- $\mu \mathrm{m}$-thick). Graphic representation (C3) of the mean \pm SEM ROD of ChAT (black) and IB4 (gray) staining (six sections, one animal). Nonspecific deposits of DAB reaction product are observed in the upper left edge of lamina I (next to the dorsal root entry zone) in $\mathbf{A 1}, \mathbf{B 1}$, and $\mathbf{C 1}$. Scale bar, $500 \mu \mathrm{m}$.

difficult to identify because they were embedded within the cholinergic plexus (Fig. 1C). In contrast, in mouse tissue, they were located in lamina III, just ventral to the lamina IIi cholinergic plexus (Fig. 2A2). In the mouse, ChAT-IR dorsal horn neurons were highly elongated in the rostrocaudal axis and were best observed in parasagittal sections (Mesnage et al., 2011). Reasoning that dorsal horn cholinergic neurons in the monkey might have a similar morphology, we used parasagittal sections to increase the probability of observing them.

Indeed, dorsal horn ChAT-IR cell bodies were more easily identified in parasagittal sections of monkey spinal cord than in transverse sections (Fig. 4B,D). As illustrated in the $3 \mathrm{D}$ reconstruction of an area of spinal cord showing the location of the ChAT-IR cell bodies and plexus, the vast majority of the neurons $(78.4 \%)$ were located within the boundaries of the fiber plexus (Fig. $4 E$ ), and not ventral to it as in the mouse. Actually, when their distribution was plotted against the dorsoventral depth of the plexus, cholinergic cell bodies were located preferentially in the dorsal half of the plexus ( $76 \%$ of neurons within the dorsal half of the plexus, Fig. $4 F$ ). We occasionally noticed the presence of some cell bodies located in lamina I and in laminae V-VI. We also found ChAT-IR cell bodies around the central canal, but these seemed to be completely independent of the dorsal horn plexus (Fig. 1A).

\section{Number of dorsal horn cholinergic cell bodies in monkey versus mouse}

Whereas the population of ChAT dorsal horn neurons is sparse in mouse, it was at first sight denser in monkey, but this impression might have been biased by the size difference between both species. We therefore aimed to provide a gross estimate of the relative density of this population in monkey and mouse. We observed, on a 1.755-mm-long lumbar segment of monkey spinal cord sectioned in the parasagittal plane, 436 ChAT-IR neuronal cell bodies within the dorsal horn cholinergic plexus or just ventral to it (Fig. 4E). This corresponds to 24.8 neurons per $50-\mu \mathrm{m}$ thick transverse section, while we reported a mean value of $2.8 \pm$ 0.3 neurons per $50-\mu \mathrm{m}$-thick transverse section in mouse (Mesnage et al., 2011). As the mean length of macaque L6-L7 segments is $\sim 5 \mathrm{~mm}$ (Thomas and Combs, 1965), we can estimate that there are 2477 dorsal horn cholinergic neurons per lumbar spinal cord segment in the adult monkey. We can compare this 
A

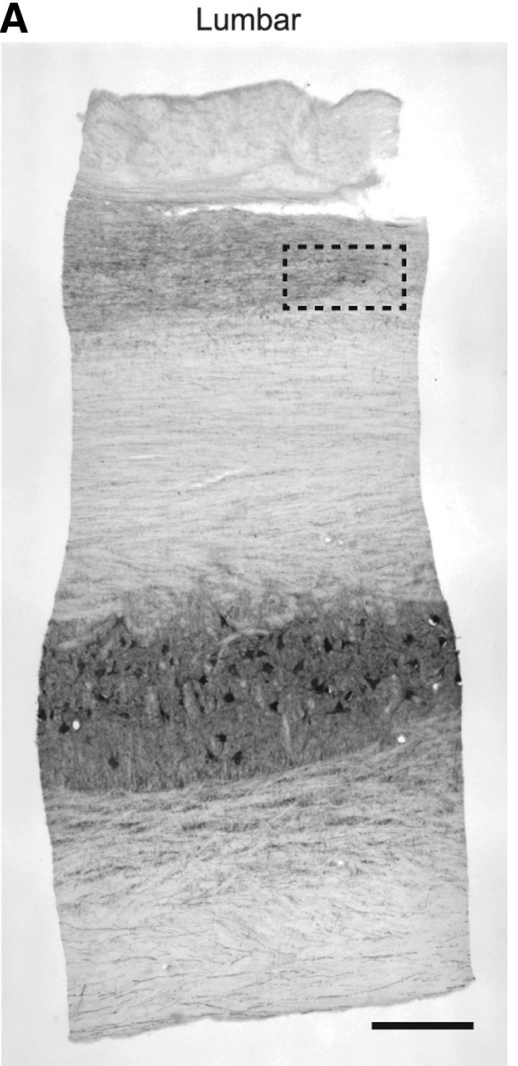

B1

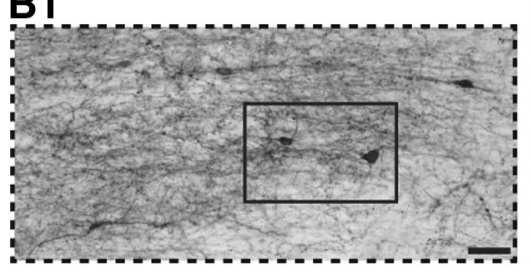

B2

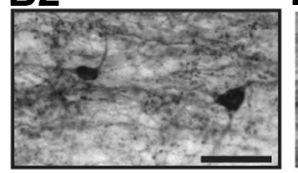

C

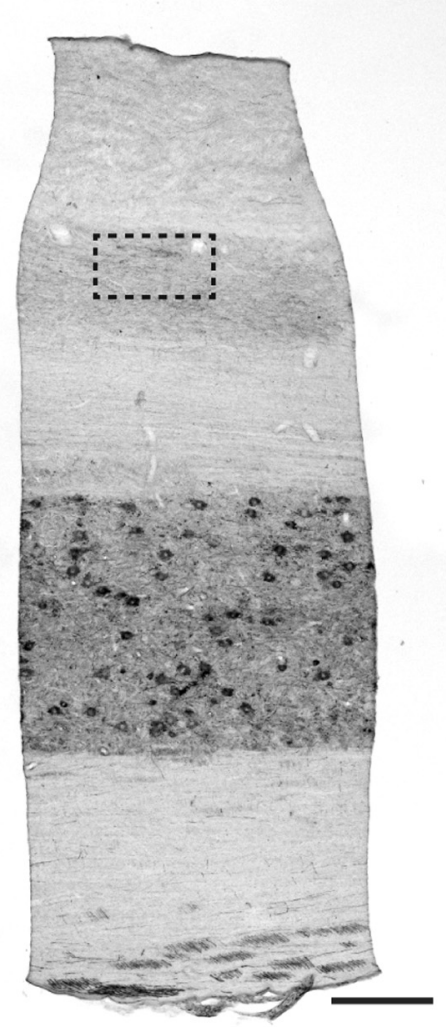

D1

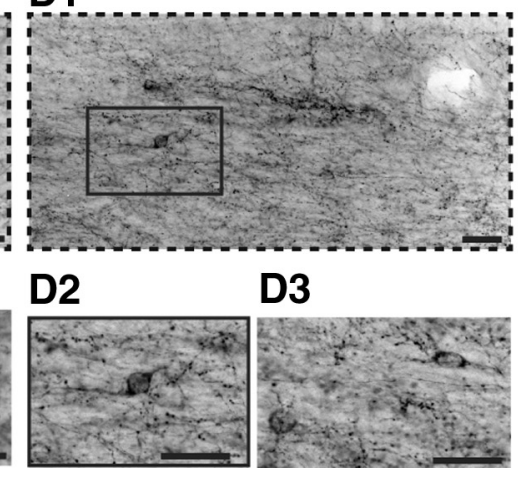

E

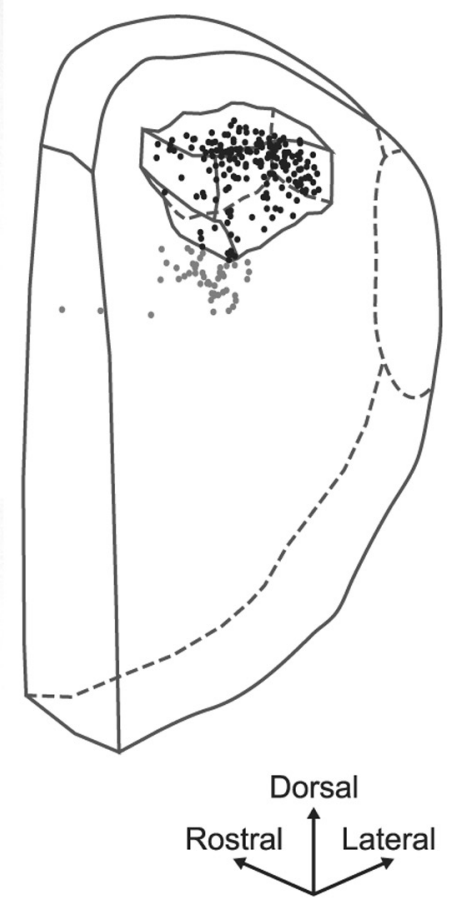

$F$

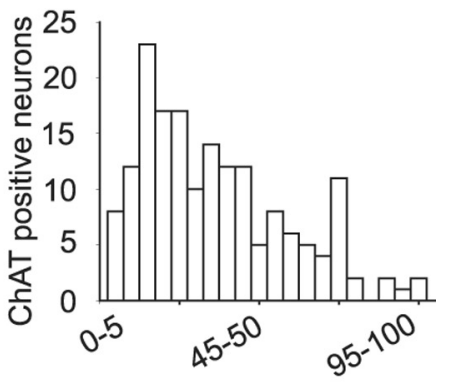

Depth (\%)

Figure 4. ChAT labeling on parasagittal sections from monkey lumbar and cervical spinal cord. $A$, Low-magnification parasagittal view of ChAT labeling in a lumbar spinal cord section (30- $\mu \mathrm{m}$-thick). B, High-magnification of ChAT-IR neurons in the dorsal horn of similar sections. B1, High-magnification view of the hyphenated region outlined in $\boldsymbol{A}$. B2, Highmagnification view of the rectangle outlined in $\boldsymbol{B}$ 1. $\boldsymbol{B}$ 3, Another high magnification view. $\boldsymbol{C}$, Low-magnification parasagittal view of ChAT labeling in a cervical spinal cord section (30- $\mu \mathrm{m}$-thick). D, High-magnification of ChAT-IR neurons in the dorsal horn of similar sections. D1, High-magnification view of the hyphenated region outlined in C. D2, Highmagnification view of the rectangle outlined in D1. D3, Another high magnification view. $\boldsymbol{E}$, The 3D localization of ChAT-IR cell bodies in the dorsal horn of a 1.76-mm-long lumbar segment of monkey spinal cord; only half of the neurons are represented for improved clarity. The borders of the ChAT-IR plexus are outlined; ChAT-IR neurons located within (respectively, outside) the plexus are represented by black (gray) dots. $F$, Distribution of ChAT-IR neurons within the ChAT-IR plexus along a dorsoventral axis. The dorsoventral position of each of the $171 \mathrm{ChAT-IR}$ neurons located within the ChAT-IR plexus in every second section ( $30-\mu \mathrm{m}$-thick) of the spinal cord fragment shown in $\boldsymbol{E}$ was noted as follows: $0 \%$ if located at the dorsal edge of the plexus and $100 \%$ if located at its ventral edge. Scale bars: $A, C, 500 \mu \mathrm{m} ; \boldsymbol{B}, \boldsymbol{D}, 50 \mu \mathrm{m}$.

value with an estimated total of 192 dorsal horn cholinergic neurons per segment in the adult mouse (considering that the average length of a lumbar segment is $3.42 \mathrm{~mm}$ for mice) (Bjugn et al., 1989). The approximate volume of a lumbar segment is 150 and $5.3 \mathrm{~mm}^{3}$ in the adult macaque monkey and mouse, respectively (Thomas and Combs, 1965; Bjugn et al., 1989). The allometric coefficient linking the number of dorsal horn cholinergic neurons in macaque monkey and mouse is therefore 0.766 , suggesting that these neurons have comparable densities in both species (see Materials and Methods).

\section{Morphological properties of monkey dorsal horn cholinergic neurons}

The fact that ChAT-IR neurons were more easily observed on parasagittal sections suggests that their main orientation is along the rostrocaudal axis, as in mouse. We further described their morphology by a quantitative analysis (see Materials and Methods; Fig. 5 and Table 1), reconstructing 10 dorsal horn ChAT-IR neurons in parasagittal sections.

The most striking observation was once more the elongated shape of the dendritic arbor along a preferential axis, as charac- 
terized by a high aspect ratio of $8.72 \pm$ 1.72 (far from the unitary value observed for radial neurons with processes evenly distributed around the cell body). The mean angle of $94.6 \pm 4.6^{\circ}$ indicates that the preferential axis is, as in mice, perpendicular to the vertical axis of the picture (i.e., rostrocaudal). There was no anisotropy of processes along the dorsoventral axis: $54.6 \pm 7.2 \%$ of the neuron area were located dorsally to the soma, whereas $45.4 \pm 7.2 \%$ were located ventrally $(p>$ 0.5 , one-sample $t$ test, $n=10$ ). Concerning the organization of the dendritic tree, the reconstructed neurons had on average $2.7 \pm 0.2$ primary dendrites and $5.2 \pm 0.5$ endings (a term encompassing both dendrites and axons). The complexity of the dendritic tree was quantified by the fractal dimension, as measured by the box counting method. For boxes between 1 and 20 $\mu \mathrm{m}$, all analyzed neurons were fractal objects. The low average fractal dimension of $1.042 \pm 0.009$ indicated a low complexity of their dendritic tree. We were able to reconstruct the dendritic arborization of monkey ChAT-IR neurons for a similar length to that of mice ChAT-GFP neurons $(p>0.1$, two-sample Wilcoxon rank-sum test).

Together, the main morphological features of the dorsal horn cholinergic neurons that we reconstructed were similar in monkey and mouse.

\section{Synaptic organization of cholinergic elements}

The analgesic effect of epidural neostigmine suggests that spinal ACh modulates pain behavior in humans. We therefore investigated the synaptic interactions between dorsal horn cholinergic fibers and anatomical elements known to be involved in nociceptive processing, such as primary sensory afferents.

Under the electron microscope, we observed axonal varicosities immunoreactive for VAChT mostly in laminae II and III. VAChT-IR boutons were very sparse in lamina I. The number of VAChT-IR varicosities per ultrathin section was never very high, and they formed only a small population of the terminals, which established symmetric synapses and displayed pleomorphic vesicles. These varicosities displayed agranular pleomorphic synaptic vesicles and, occasionally, one or two dense-core vesicles and established mostly symmetric synapses with dendritic profiles (Fig. 6) and, occasionally, with cell bodies (data not shown). Some VAChT-IR profiles represented peripheral elements in synaptic glomeruli, where they were presynaptic to the central element and/or to glomerular dendrites (Fig. 6B, C). VAChT-IR vesicle-containing profiles were associated both with the smaller glomeruli with a central bouton displaying a dense cytoplasmic matrix and agranular synaptic vesicles of several diameters (type I; Fig. $6 \mathrm{~B}, \mathrm{C}$ ) and with the larger glomeruli displaying a central bouton with a light matrix and vesicles of uniform size (type II; data not shown). VAChT immunoreactivity was also detected in a low number of proximal dendrites in laminae II-III and occasionally in distal dendrites, which were rarely part of synaptic glomeruli (Fig. 6D). Weak VAChT-IR was sometimes observed in cell bodies in the same layers (data not shown), but it was never observed in glial cell processes. However, on occasion, VAChT-IR profiles were apposed to the astrocytic processes (Fig. 6A).
When the immunostaining for GABA was added using a postembedding protocol in material previously stained for VAChT immunoreactivity, we observed that all the VAChT-IR varicosities were also immunoreactive for GABA (Fig. 7). However, most GABA-IR boutons did not display VAChT immunoreactivity.

This EM analysis therefore suggests that dorsal horn cholinergic boutons are also GABAergic and are involved in the presynaptic inhibition of nociceptive and non-nociceptive primary afferent information in monkey, as previously shown in rats.

\section{Discussion}

We provide the first demonstration that cholinergic cell bodies and processes are present in the spinal dorsal horn of macaque monkeys. The cholinergic processes formed synapses on dendrites and primary afferent terminals and are the probable source of ACh that mediates the analgesic effect of epidural AChE inhibitors. The morphological features of this newly identified cholinergic spinal dorsal horn system in primates support its potential involvement in sensory and nociception modulation at the level of the spinal cord. Our data open new important avenues for the development of novel therapeutic strategies for pain management.

Identification of a dorsal horn cholinergic system in primates Previous studies investigated the presence of cholinergic neurons in the primate spinal cord, using anti-ChAT (Hedreen et al., 1983; Ichikawa and Shimizu, 1998) and anti-VAChT (Schafer et al., 1995) antibodies. In contrast with what was described in rodents (Barber et al., 1984; Ribeiro-da-Silva and Cuello, 1990; Todd, 1991; Mesnage et al., 2011), none of these studies mentions the existence of cholinergic neurons and/or fibers in monkey dorsal horn. We used different antibodies from those of the above studies (see Materials and Methods), which had been successfully used in monkey to label, respectively, motor endplates and parasympathetic fibers (Ruocco et al., 2002; Ugolini et al., 2006). We used both transverse and parasagittal sections because cholinergic cell bodies were much more easily visualized in parasagittal sections because of their specific morphology. It was the use of the parasagittal sections and of a different anti-ChAT antibody that allowed the identification of this population of dorsal horn cholinergic neurons that had been so far overlooked in the monkey. However, it should be mentioned that a study in humans, 
Table 1. Morphometric features of ChAT-IR dorsal horn neurons from monkey ( $n=10$ neurons) ${ }^{a}$

\begin{tabular}{|c|c|c|c|c|c|c|c|c|c|}
\hline Solidity & Aspect ratio & Angle $\left({ }^{\circ}\right)$ & $\begin{array}{l}\text { Fractal } \\
\text { dimension }\end{array}$ & L total $(\mu \mathrm{m})$ & $\begin{array}{l}\text { No. of primary } \\
\text { dendrites }\end{array}$ & $\begin{array}{l}\text { No. of } \\
\text { endings }\end{array}$ & $\begin{array}{l}\text { L soma } \\
(\mu \mathrm{m})\end{array}$ & $\begin{array}{l}\text { I soma } \\
(\mu \mathrm{m})\end{array}$ & $\%$ dorsal \\
\hline $0.011 \pm 0.004$ & $8.72 \pm 1.72$ & $94.6 \pm 4.6$ & $1.040 \pm 0.009$ & $326.9 \pm 29.1$ & $2.7 \pm 0.2$ & $5.2 \pm 0.5$ & $18.8 \pm 0.8$ & $10.5 \pm 0.7$ & $54.6 \pm 7.2$ \\
\hline
\end{tabular}

${ }^{a}$ Data are mean \pm SEM. The analysis was performed on projection in the parasagittal plane of neurons reconstructed using their ChAT immunoreactivity ( $\left.n=10\right)$. See Materials and Methods for the calculation of first four parameters. $L$ total, rostrocaudal length of the neuron; No. of primary dendrites, number of processing arising directly from the cell body; №. of endings, number of final processes; $L$ and I soma, rostrocaudal and dorsoventral, respectively, maximal size of ChAT-IR somata; \% dorsal, percentage of the neuronal surface located dorsally to the soma.

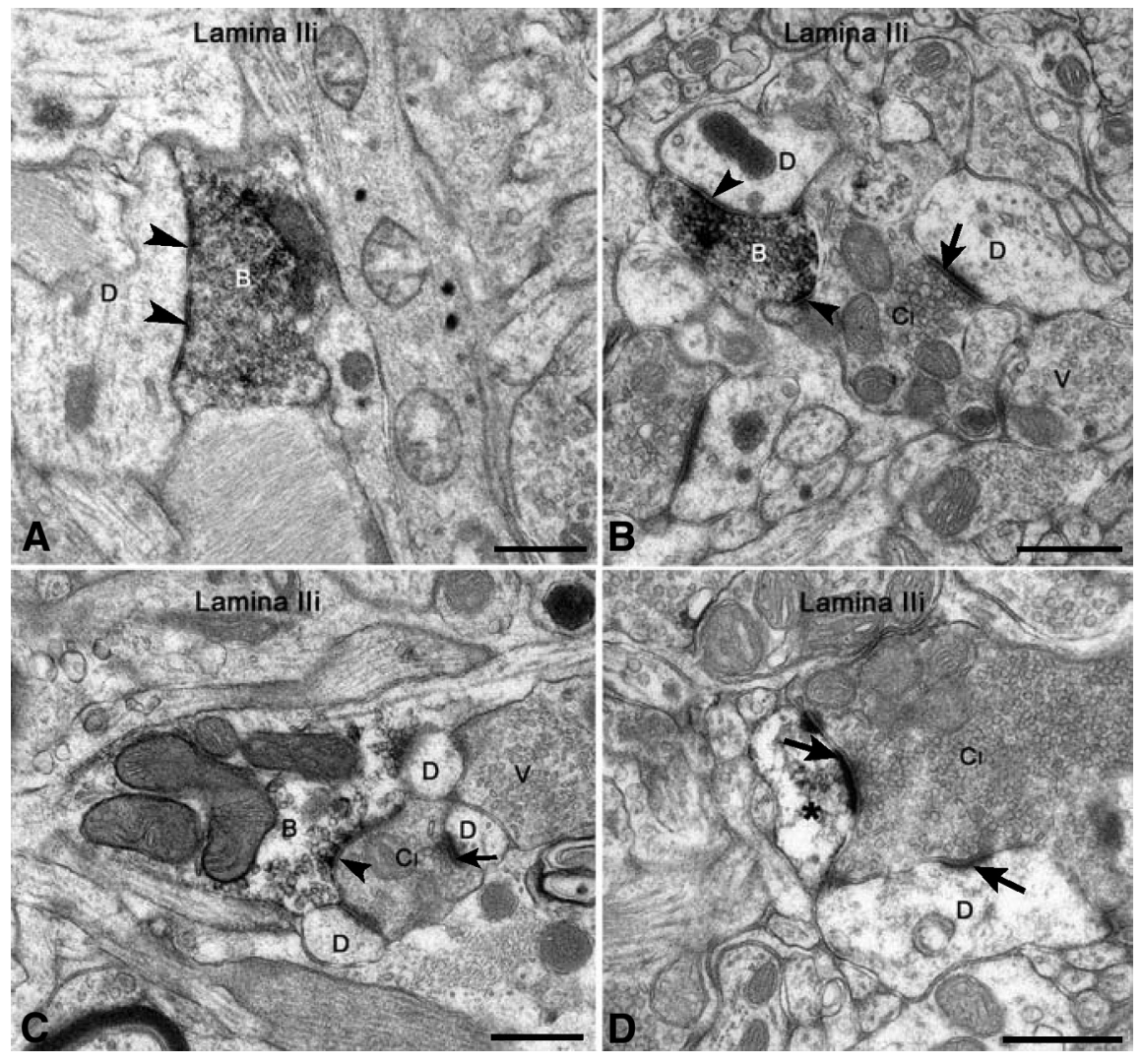

Figure 6. Ultrastructure of VAChT-IR profiles in lamina II of monkey spinal cord. $A$, In a parasagittal section, observe a VAChT-IR bouton (B) establishing a symmetric synapse with a dendrite (D) and apposed to an astrocytic process (G). $\boldsymbol{B}, \boldsymbol{C}$, The central boutons of type I glomeruli $\left(C_{1}\right)$ are postsynaptic to VAChT-IR profiles $(B)$ and are also in apposition with unlabeled boutons displaying pleomorphic synaptic vesicles (V); the VAChT-IR profiles also contact glomerular dendrites (D). D, A VAChT-IR dendrite $\left(^{*}\right)$ is postsynaptic to the central bouton of a type I glomerulus $\left(C_{1}\right)$. Arrowheads indicate symmetric synapses, and arrows indicate asymmetric contacts. Scale bars, $0.5 \mu \mathrm{m}$.

using the same antibody that we used, reported ChAT-IR fibers and/or cell bodies in the dorsal cord of some individuals (Gill et al., 2007). Together, these data strongly suggest that there is a population of cholinergic neurons and fibers in the spinal dorsal horn of nonhuman primates and of the human.

We believe that the cholinergic neurons and processes we describe in laminae II-III release the ACh whose concentration is increased after epidural injection of AChE inhibitors, such as neostigmine, and the substrate of the analgesic effect of this drug. However, we cannot entirely rule out the participation of ACh from other sources, such as from neurons located more ventrally in the transition of the dorsal and ventral horn (e.g., those around the central canal) or in the ventral horn itself. However, these neurons are not expected to project dorsally; in rat, they have been shown to project ventrally and likely contribute only to motor control (Bertrand and Cazalets, 2011). We cannot rule out a participation of cholinergic neurons from other spinal segments that might project to the plexus we described. Indeed, there is evidence that neurons of the sympathetic-related inter- mediomedialis nucleus, located next to the central canal in spinal segments known to have preganglionic sympathetic neurons, send ascending and descending axons (Matsushita et al., 1979) and receive a strong input from lumbar lamina I neurons bilaterally (Craig, 1993). Therefore, it is possible that the axons of sympathetic preganglionic neurons from other spinal segments project to superficial layers and might contribute to the cholinergic plexus in laminae II-III. Yet, the colocalization with GABA in all the cholinergic terminals of the plexus we studied at the EM level makes it unlikely that some of the axons we observed might be of sympathetic preganglionic origin or arise from primary afferents.

\section{Comparison of the dorsal horn cholinergic system in primates versus rodents}

The dorsal horn cholinergic system in monkeys differed from that in rodents. First, the plexus of cholinergic fibers was much thicker in monkey, encompassing both laminae II and III, whereas it was mostly restricted to inner lamina II in mice (Mesnage et al., 2011). The comparison of the localization of this plexus to classical lamination markers of the dorsal horn led us to provide the first description of IB4 staining in the monkey (described in the human by Eftekhari and Edvinsson, 2011) and of PKC $\gamma$ staining in primates. The relative position of the ChAT plexus compared with CGRP, PKC $\gamma$, or IB4 staining differed in primates compared with rodents, in agreement with the greater thickness of the ChAT plexus in the former.

There were also differences in the location of cholinergic cell bodies. In the monkey, they were found in laminae II-III, within the boundaries of the cholinergic plexus, whereas they were located in laminae III-IV in rodents, ventrally to the cholinergic plexus (Mesnage et al., 2011). As primary afferents terminate in similar layers in primates and rodents, as assessed by our CGRP and IB4 stainings, differences in localization of cholinergic cell bodies and fibers might suggest different connectivity within the dorsal horn sensory network. Our EM analyses, however, do not support this hypothesis (see below).

Despite the differences, we decided to compare the density of dorsal horn cholinergic neurons in primates and rodents with the aim of finding out whether the dorsal horn cholinergic system could have a comparable relevance in both species. Interestingly, our data suggest that the density of dorsal horn cholinergic neu- 
rons in the monkey is similar to the one in mouse when the difference in size of the two species is taken into account. The concept that the dorsal horn cholinergic system has similar functions in mouse and primate is supported by the comparable analgesic effects of intrathecal AChE inhibitors in rodents and humans.

The main morphometric properties of cholinergic neurons (i.e., the predominant rostrocaudal extension of their dendritic tree and their limited complexity) were comparable in monkey and mouse. Yet, in the mouse, the cholinergic neurons were located ventrally to the cholinergic plexus, and their dendrites had a preferential dorsal outgrowth to reach the plexus. This feature was not observed in the monkey, where cholinergic cell bodies were located within the plexus and their dendrites were on average distributed

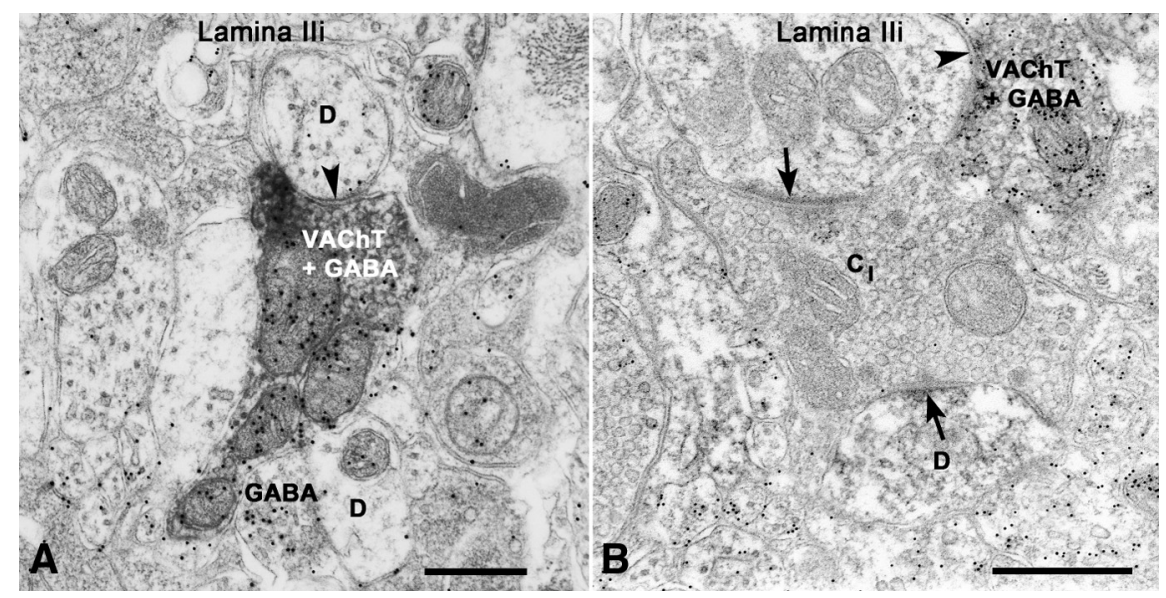

Figure 7. Demonstration of the colocalization of GABA and VAChT immunoreactivities at the EM level. $\boldsymbol{A}$, Bouton doublelabeled for VAChT and GABA immunoreactivities establishes a symmetric synapse (arrowhead) with an unlabeled dendrite (D). $\boldsymbol{B}$, Double-labeled vesicle-containing profile (VAChT $+G A B A)$ is apposed to the central bouton of a type I glomerulus $\left(C_{1}\right)$ and presynaptic at a symmetric synapse (arrowhead) to one of the two unlabeled glomerular dendrites (D), which are postsynaptic to the $C_{\text {I }}$ at asymmetric synapses (arrows). Scale bars, $0.5 \mu \mathrm{m}$. equally along the dorsoventral axis. The

morphological features of the cholinergic neurons from lamina II of the monkey spinal cord suggest those of the islet cells described using the Golgi method in the medullary dorsal horn of the cat (Gobel, 1978) and in the human spinal cord (Schoenen, 1982).

\section{Synaptic connectivity of dorsal horn cholinergic neurons in primates}

We analyzed the connections established by cholinergic boutons in the monkey dorsal horn as it reveals the position of cholinergic interneurons within the dorsal horn sensory network. We used an antibody against VAChT instead of ChAT because previous reports have shown that VAChT is the preferred cholinergic marker for cholinergic terminals in the CNS (Weihe et al., 1996; Turrini et al., 2001; Allard et al., 2012). The laminar distribution of cholinergic boutons and dendritic profiles were identical in cervical and lumbar sections, and very similar to those from a previous study of one of us in the rat spinal cord (Ribeiro-daSilva and Cuello, 1990). Cholinergic boutons established mostly axo-dendritic and occasionally axo-somatic synapses, possessed pleomorphic agranular synaptic vesicles, and established symmetric synapses. These features suggest an inhibitory function, which was confirmed by our observation that all cholinergic profiles were also GABAergic. Dorsal horn cholinergic neurons and terminals in mice and rats similarly colocalized GABA immunoreactivity (Todd, 1991; Ribeiro-da-Silva, 2004; Mesnage et al., 2011). Also, in agreement with previous data from the rat (Ribeiro-da-Silva and Cuello, 1990), we observed cholinergic boutons presynaptic to the central element of synaptic glomeruli of types I and II, which are known to be of primary sensory origin (Ribeiro-da-Silva and De Koninck, 2008). In rat, the central boutons of type I glomeruli represent the central terminals of nonpeptidergic nociceptive primary afferents, whereas those in type II have been considered non-nociceptive (Ribeiro-da-Silva and De Koninck, 2008), although this needs to be confirmed in primate. However, it can be suggested that cholinergic boutons are involved in the presynaptic inhibition of nociceptive and nonnociceptive primary afferent information both in rodents and primates.

\section{Functional relevance}

Spinal ACh levels are important for nociceptive behavior in rodents, and their elevation induces analgesia (Naguib and Yaksh, 1994; Jones and Dunlop, 2007). Locally decreasing the level of ACh or blocking cholinergic signaling exacerbates nociceptive responses (hyperalgesia) and/or induces a nociceptive behavior after an innocuous stimulation (allodynia) (Zhuo and Gebhart, 1991; Hama and Menzaghi, 2001; Rashid and Ueda, 2002; Matsumoto et al., 2007). In addition, chronic peripheral neuropathies are associated with a decrease in spinal cholinergic tone (Rashid and Ueda, 2002). We have recently identified a population of cholinergic interneurons in mouse dorsal horn as the likely main source of ACh (Mesnage et al., 2011). The present study demonstrates that a comparable cholinergic network exists in the primate dorsal horn. This observation opens important therapeutic avenues. First, it identifies the possible source of ACh involved in the analgesic effects of epidural AChE inhibitors increasingly used in clinical practice. Second, that cholinergic terminals are presynaptic to primary afferents indicates that they likely modulate incoming somatosensory information. This observation supports the interest of targeting the spinal cholinergic system for novel clinical analgesic strategies.

\section{References}

Adams JC (1981) Heavy metal intensification of DAB-based HRP reaction product. J Histochem Cytochem 29:775. CrossRef Medline

Allard S, Leon WC, Pakavathkumar P, Bruno MA, Ribeiro-da-Silva A, Cuello AC (2012) Impact of the NGF maturation and degradation pathway on the cortical cholinergic system phenotype. J Neurosci 32:2002-2012. CrossRef Medline

Aquilonius SM, Eckernäs SA, Gillberg PG (1981) Topographical localization of choline acetyltransferase within the human spinal cord and a comparison with some other species. Brain Res 211:329-340. CrossRef Medline

Barber RP, Phelps PE, Houser CR, Crawford GD, Salvaterra PM, Vaughn JE (1984) The morphology and distribution of neurons containing choline acetyltransferase in the adult rat spinal cord: an immunocytochemical study. J Comp Neurol 229:329-346. CrossRef Medline

Bernard F, Bossu JL, Gaillard S (2001) Identification of living oligodendrocyte developmental stages by fractal analysis of cell morphology. J Neurosci Res 65:439-445. CrossRef Medline

Bertrand SS, Cazalets JR (2011) Cholinergic partition cells and lamina $\times$ neurons induce a muscarinic-dependent short-term potentiation of com- 
missural glutamatergic inputs in lumbar motoneurons. Front Neural Circuits 5:15. CrossRef Medline

Bjugn R, Bøe R, Haugland HK (1989) A stereological study of the ependyma of the mouse spinal cord: with a comparative note on the choroid plexus ependyma. J Anat 166:171-178. Medline

Carlton SM, McNeill DL, Chung K, Coggeshall RE (1987) A light and electron microscopic level analysis of calcitonin gene-related peptide (CGRP) in the spinal cord of the primate: an immunohistochemical study. Neurosci Lett 82:145-150. CrossRef Medline

Chen SR, Pan HL (2001) Spinal endogenous acetylcholine contributes to the analgesic effect of systemic morphine in rats. Anesthesiology 95:525530. CrossRef Medline

Cordero-Erausquin M, Allard S, Dolique T, Bachand K, Ribeiro-da-Silva A, De Koninck Y (2009) Dorsal horn neurons presynaptic to lamina I spino-parabrachial neurons revealed by transsynaptic labelling. J Comp Neurol 517:601-615. CrossRef Medline

Craig AD (1993) Propriospinal input to thoracolumbar sympathetic nuclei from cervical and lumbar lamina I neurons in the cat and the monkey. J Comp Neurol 331:517-530. CrossRef Medline

Eftekhari S, Edvinsson L (2011) Calcitonin gene-related peptide (CGRP) and its receptor components in human and rat spinal trigeminal nucleus and spinal cord at C1-level. BMC Neurosci 12:112. CrossRef Medline

Eisenach JC (2009) Epidural neostigmine: will it replace lipid soluble opioids for postoperative and labor analgesia? Anesth Analg 109:293-295. CrossRef Medline

Gagliardo KM, De Carvalho Balieiro JC, De Souza RR, Ribeiro AA (2005) Postnatal-related changes in the size and total number of neurons in the caudal mesenteric ganglion of dogs: total number of neurons can be predicted from body weight and ganglion volume. Anat Rec A Discov Mol Cell Evol Biol 286:917-929. CrossRef Medline

Gill SK, Ishak M, Dobransky T, Haroutunian V, Davis KL, Rylett RJ (2007) $82-\mathrm{kDa}$ choline acetyltransferase is in nuclei of cholinergic neurons in human CNS and altered in aging and Alzheimer disease. Neurobiol Aging 28:1028-1040. CrossRef Medline

Gilmor ML, Nash NR, Roghani A, Edwards RH, Yi H, Hersch SM, Levey AI (1996) Expression of the putative vesicular acetylcholine transporter in rat brain and localization in cholinergic synaptic vesicles. J Neurosci 16: 2179-2190. Medline

Gobel S (1978) Golgi studies of the neurons in layer II of the dorsal horn of the medulla (trigeminal nucleus caudalis). J Comp Neurol 180:395-413. CrossRef Medline

Habib AS, Gan TJ (2006) Use of neostigmine in the management of acute postoperative pain and labour pain: a review. CNS Drugs 20:821-839. CrossRef Medline

Hama A, Menzaghi F (2001) Antagonist of nicotinic acetylcholine receptors (nAChR) enhances formalin-induced nociception in rats: tonic role of nAChRs in the control of pain following injury. Brain Res 888:102-106. CrossRef Medline

Hedreen JC, Bacon SJ, Cork LC, Kitt CA, Crawford GD, Salvaterra PM, Price DL (1983) Immunocytochemical identification of cholinergic neurons in the monkey central nervous system using monoclonal antibodies against choline acetyltransferase. Neurosci Lett 43:173-177. CrossRef Medline

Ichikawa T, Shimizu T (1998) Organization of choline acetyltransferasecontaining structures in the cranial nerve motor nuclei and spinal cord of the monkey. Brain Res 779:96-103. CrossRef Medline

Jones PG, Dunlop J (2007) Targeting the cholinergic system as a therapeutic strategy for the treatment of pain. Neuropharmacology 53:197-206. CrossRef Medline

Kayser C, Heusner A (1964) [Comparative study of energy metabolism in the animal kingdom]. J Physiol (Paris) 56:489-524. Medline

Loesch A, Mayhew TM, Tang H, Ladd FV, Ladd AA, de Melo MP, da Silva AA, Coppi AA (2010) Stereological and allometric studies on neurons and axo-dendritic synapses in the superior cervical ganglia of rats, capybaras and horses. Cell Tissue Res 341:223-237. CrossRef Medline

Lorenzo LE, Ramien M, St Louis M, De Koninck Y, Ribeiro-da-Silva A (2008) Postnatal changes in the Rexed lamination and markers of nociceptive afferents in the superficial dorsal horn of the rat. J Comp Neurol 508:592-604. CrossRef Medline

Matsumoto M, Xie W, Inoue M, Ueda H (2007) Evidence for the tonic inhibition of spinal pain by nicotinic cholinergic transmission through primary afferents. Mol Pain 3:41. CrossRef Medline
Matsushita M, Ikeda M, Hosoya Y (1979) The location of spinal neurons with long descending axons (long descending propriospinal tract neurons) in the cat: a study with the horseradish peroxidase technique. J Comp Neurol 184:63-80. CrossRef Medline

Mayhew TM (1991) Accurate prediction of Purkinje cell number from cerebellar weight can be achieved with the fractionator. J Comp Neurol 308:162-168. CrossRef Medline

Mesnage B, Gaillard S, Godin AG, Rodeau JL, Hammer M, Von Engelhardt J, Wiseman PW, De Koninck Y, Schlichter R, Cordero-Erausquin M (2011) Morphological and functional characterization of cholinergic interneurons of the dorsal horn of the mouse spinal cord. J Comp Neurol 519:3139-3158. CrossRef Medline

Naguib M, Yaksh TL (1994) Antinociceptive effects of spinal cholinesterase inhibition and isobolographic analysis of the interaction with mu and $\alpha 2$ receptor systems. Anesthesiology 80:1338-1348. CrossRef Medline

Oda Y, Muroishi Y, Misawa H, Suzuki S (2004) Comparative study of gene expression of cholinergic system-related molecules in the human spinal cord and term placenta. Neuroscience 128:39-49. CrossRef Medline

Pagel MD, Harvey PH (1988) Recent developments in the analysis of comparative data. Q Rev Biol 63:413-440. CrossRef Medline

Paqueron X, Li X, Bantel C, Tobin JR, Voytko ML, Eisenach JC (2001) An obligatory role for spinal cholinergic neurons in the antiallodynic effects of clonidine after peripheral nerve injury. Anesthesiology 94:1074-1081. CrossRef Medline

Polgár E, Fowler JH, McGill MM, Todd AJ (1999) The types of neuron which contain protein kinase $\mathrm{C} \gamma$ in rat spinal cord. Brain Res 833:71-80. CrossRef Medline

Rashid MH, Ueda H (2002) Neuropathy-specific analgesic action of intrathecal nicotinic agonists and its spinal GABA-mediated mechanism. Brain Res 953:53-62. CrossRef Medline

Ribeiro-da-Silva A (2004) Substantia gelatinosa of the spinal cord. In: The rat nervous system (Paxinos G, ed), pp 129-148. San Diego: Elsevier Academic.

Ribeiro-da-Silva A, Cuello AC (1990) Choline acetyltransferase-immunoreactive profiles are presynaptic to primary sensory fibers in the rat superficial dorsal horn. J Comp Neurol 295:370-384. CrossRef Medline

Ribeiro-da-Silva A, De Koninck Y (2008) Morphological and neurochemical organization of the spinal dorsal horn. In: The senses: a comprehensive reference (Basbaum AI, Bushnell MC, eds), pp 279-310. New York: Academic.

Ribeiro-da-Silva A, Priestley JV, Cuello AC (1993) Pre-embedding ultrastructural immunocytochemistry. In: Immunohistochemistry II (Cuello AC, ed), pp 181-227. Chichester, United Kingdom: Wiley.

Ruocco I, Cuello AC, Parent A, Ribeiro-da-Silva A (2002) Skin blood vessels are simultaneously innervated by sensory, sympathetic, and parasympathetic fibers. J Comp Neurol 448:323-336. CrossRef Medline

Russ JC (1999) The image processing handbook. Boca Raton, FL: CRC.

Schafer MK, Weihe E, Erickson JD, Eiden LE (1995) Human and monkey cholinergic neurons visualized in paraffin-embedded tissues by immunoreactivity for VAChT, the vesicular acetylcholine transporter. J Mol Neurosci 6:225-235. CrossRef Medline

Schoenen J (1982) The dendritic organization of the human spinal cord: the dorsal horn. Neuroscience 7:2057-2087. CrossRef Medline

Syverud K, Chinga G, Johnsen PO, Leirset I, Wiik K (2007) Analysis of lint particles from full-scale printing trials. Appita J 60:286-290.

Takeda T, Ishikawa A, Ohtomo K, Kobayashi Y, Matsuoka T (1992) Fractal dimension of dendritic tree of cerebellar Purkinje cell during onto- and phylogenetic development. Neurosci Res 13:19-31. CrossRef Medline

Thomas CE, Combs CM (1965) Spinal cord segments. B. Gross structure in the adult monkey. Am J Anat 116:205-216. CrossRef Medline

Todd AJ (1991) Immunohistochemical evidence that acetylcholine and glycine exist in different populations of GABAergic neurons in lamina III of rat spinal dorsal horn. Neuroscience 44:741-746. CrossRef Medline

Turrini P, Casu MA, Wong TP, De Koninck Y, Ribeiro-da-Silva A, Cuello AC (2001) Cholinergic nerve terminals establish classical synapses in the rat cerebral cortex: synaptic pattern and age-related atrophy. Neuroscience 105:277-285. CrossRef Medline

Ugolini G, Klam F, Doldan Dans M, Dubayle D, Brandi AM, Büttner-Ennever J, Graf W (2006) Horizontal eye movement networks in primates as revealed by retrograde transneuronal transfer of rabies virus: differences in monosynaptic input to "slow" and "fast" abducens motoneurons. J Comp Neurol 498:762-785. CrossRef Medline 
Weihe E, Tao-Cheng JH, Schäfer MK, Erickson JD, Eiden LE (1996) Visualization of the vesicular acetylcholine transporter in cholinergic nerve terminals and its targeting to a specific population of small synaptic vesicles. Proc Natl Acad Sci U S A 93:3547-3552. CrossRef Medline
Zhuo M, Gebhart GF (1991) Tonic cholinergic inhibition of spinal mechanical transmission. Pain 46:211-222. CrossRef Medline 